\title{
A method to correct the flow distortion of offshore wind data using CFD simulation and experimental wind tunnel tests
}

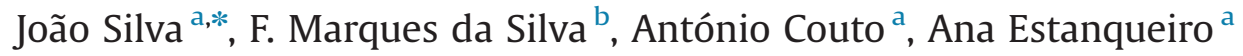 \\ ${ }^{a}$ Energy Analysis and Networks Unit National, Laboratory for Energy and Geology, Lisbon, Portugal \\ ${ }^{\mathrm{b}}$ Earthquake Engineering and Structural Dynamics Division, National Laboratory for Civil Engineering, Lisbon, Portugal
}

\section{A R T I C L E I N F O}

\section{Article history:}

Received 1 August 2014

Received in revised form

22 January 2015

Accepted 27 January 2015

Available online 3 March 2015

Keywords:

Offshore wind profile

Wind flow over hill

CFD simulation

Wind tunnel

\begin{abstract}
A B S T R A C T
The assessment of wind energy resource for the development of deep offshore wind plants requires the use of every possible source of data and, in many cases, includes data gathered at meteorological stations installed at islands, islets or even oil platforms-all structures that interfere with, and change, the flow characteristics. This work aims to contribute to the evaluation of such changes in the flow by developing a correction methodology and applying it to the case of Berlenga island, Portugal. The study is performed using computational fluid dynamic simulations (CFD) validated by wind tunnel tests. In order to simulate the incoming offshore flow with CFD models a wind profile, unknown a priori, was established using observations from two coastal wind stations and a power law wind profile was fitted to the existing data $(\alpha=0.165)$. The results show that the resulting horizontal wind speed at $80 \mathrm{~m}$ above sea level is $16 \%$ lower than the wind speed at $80 \mathrm{~m}$ above the island for the dominant wind direction sector. (c) 2015 Elsevier Ltd. All rights reserved.
\end{abstract}

\section{Introduction}

Offshore wind energy generation has increased in Europe in the last few years mainly due to the fact that, in most countries, the remaining onshore sites introduce serious social and environmental impacts. Moreover, in general, wind potential is higher offshore than onshore and is characterized by more constant and less turbulent winds (Hoeven, 2013; Estanqueiro et al., 2014). On the other hand, offshore deployments involve larger investment costs and several coastal regions may not have enough wind potential to become a viable investment. Reliable wind measures in deep offshore regions are extremely important considering the total amount of investment and the high technical and financial risks associated with the challenging ocean environment (Hasager et al., 2013). The actual approach for deep offshore wind resource evaluation is based on the use of long term simulations through high resolution numerical weather prediction models (Costa et al., 2006), floating met ocean buoys which measure at $2 \mathrm{~m}$ above sea level (Sheridan et al., 2012) or the combination of both (Schwartz et al., 2010). However, these approaches present serious limitations in what concerns: a) their reduced accuracy; b) the vulnerability of the experimental setup to the marine environment; and c) the high costs of the foundation for a fixed bottom met mast installation or a floating buoy.

New methodologies, capable of assessing the offshore wind resource more cost efficiently and with added accuracy are

\footnotetext{
* Corresponding author.

E-mail address: joao.silva@Ineg.pt (J. Silva).
}

strongly needed. For instance, in Estanqueiro et al. (2014) a methodology based on a site calibration embedded with time shift between two measurement points (one onshore met mast and one floating LiDAR) shows a promising improvement in the accuracy of the deep-offshore wind energy resource assessment. Recently some authors showed that oil rigs, islands or islets can and should be used as a base for installing wind measurement devices allowing to perform long term measurements with relatively low cost and evaluate accurately the deep-offshore wind resource (e.g. Hasager et al. (2013) and Stickland et al. (2013)). However, as described by these authors additional challenges may arise as these structures act as an obstacle to wind flow; therefore it becomes mandatory to correct the disturbances (changes in the intensity and vertical shape of the incoming wind profile) created by the obstacle, or the orography of an islet, in order to obtain the correct characteristics of the wind flow over the sea. The sensible approach to assess the necessary correction is based on a joint analysis using physical experiments (wind tunnel) and CFD simulations (Blocken, 2014). This coupled analysis is necessary in order to validate CFD simulations (Blocken, 2014; Zhang, 2009) and, at the same time, it allows tuning the best parameterizations and options to run the CFD models.

The application of CFD models in the wind sector has significantly increased in the latest years. These models present several advantages over wind tunnel tests (Blocken, 2014) since, at reduced costs they allow: a) to obtain detailed three dimensional flow studies of the entire domain and not just in some specific points where there are measuring instruments; and b) to obtain 